\title{
Diagnosis and Management of Postoperative Conversion Disorder in an Adolescent Following Arthroscopic Meniscectomy
}

\author{
Mohammed Hakim ${ }^{\mathrm{a}, \mathrm{d}}$, Kevin Klingele ${ }^{\mathrm{b}}$, Dmitry Tumin ${ }^{\mathrm{a}}$, Joseph D. Tobias ${ }^{\mathrm{a}, \mathrm{c}}$, \\ Tarun Bhalla ${ }^{a, c}$
}

\begin{abstract}
Conversion disorder (CD), also known as a functional neurological symptom disorder, is a somatoform disorder involving an unconscious, involuntary process in which psychosocial needs, conflicts, and internal stresses are expressed as somatic symptoms without an anatomical or physiological explanation. The signs and symptoms are involuntary and appear with no underlying physical cause. Various triggers and psychologic stresses may result in the sudden clinical manifestations of the disorder. We present a 14-year-old adolescent who developed a $\mathrm{CD}$ following anesthetic care for a partial lateral meniscectomy. Previous reports of postoperative CDs are reviewed, etiologic considerations during the postoperative period are discussed, and management options are presented.
\end{abstract}

Keywords: Conversion disorder; Somatoform disorder; Partial lateral meniscectomy

\section{Introduction}

Conversion disorder (CD) has been defined as a somatoform disorder involving an unconscious, involuntary process in which psychosocial needs, conflicts, and stresses are expressed as somatic symptoms with no anatomical or physiological explanation [1]. The clinical signs and symptoms are involuntary, appearing with no underlying physical cause. Various triggers and psychologic stresses may result in the sudden clinical

Manuscript submitted September 5, 2017, accepted September 20, 2017

aDepartment of Anesthesiology and Pain Medicine, Nationwide Children's Hospital, Columbus, OH, USA

bDepartment of Orthopedic Surgery, Nationwide Children's Hospital and The Ohio State University, Columbus, OH, USA

'Department of Anesthesiology and Pain Medicine, The Ohio State University, Columbus, OH, USA

${ }^{\mathrm{d} C o r r e s p o n d i n g ~ A u t h o r: ~ M o h a m m e d ~ H a k i m, ~ D e p a r t m e n t ~ o f ~ A n e s t h e s i o l o g y ~}$ and Pain Medicine, Nationwide Children's Hospital, 700 Children's Drive, Columbus, $\mathrm{OH} 43205$, USA.

Email: mohammed.hakim@nationwidechildrens.org

doi: https://doi.org/10.14740/jmc2905w manifestations of the disorder in patients with no prior psychiatric history. Risk factors for the development of CD include a previous history of depression, dissociative disorders, anxiety, cognitive dysfunction, and preceding traumatic experiences [2-5]. The female to male ratio is 10:1 [5].

There are a limited number of reports of perioperative CDs in pediatric patients undergoing a variety of surgical procedures (Table 1) [6-10]. The development of CD during the postoperative period presents many unique challenges for the perioperative care team. Many of the signs and symptoms are vague with limited objective findings and may be attributed to sequelae from the anesthetic care or surgical procedure. We present a 14-year-old adolescent who developed CD following anesthetic care for a partial lateral meniscectomy. Previous reports of postoperative $\mathrm{CDs}$ are reviewed, etiologic considerations during the postoperative period are discussed, and management options are presented.

\section{Case Report}

Institutional Review Board approval is not required at Nationwide Children's Hospital (Columbus, $\mathrm{OH}$ ) for the presentation of a single case report. The patient was a 14-year-old, 59 $\mathrm{kg}$ girl who presented initially with rigors, acute delirium and agitation following a general anesthetic and single shot femoral nerve block for a left arthroscopic partial lateral meniscectomy. Her past surgical history included an open reduction and internal fixation with trochanteric nailing of her femur 18 months ago. Her recovery from that surgery was initially described as uneventful; however, it was later discovered that she had persistent hyperventilation and anxiety for approximately $12 \mathrm{~h}$ postoperatively. At the time of the partial lateral meniscectomy, current home medications included acetaminophen and isotretinoin. The patient is a very competitive athlete and competed in swimming at both the state and national level. Preoperative physical examination revealed a young woman with left knee pain. She was in no acute distress. Airway and physical examination were normal. Immediately before being transported to the operating room, the patient was told by her surgeon that she could not return to swimming for at least 6 weeks, which caused her to be extremely anxious. The patient was transported to the operating room and routine American Society of Anesthesiologists' monitors were ap- 
Table 1. Reports of Postoperative Conversion Disorders in Children

\begin{tabular}{|c|c|c|}
\hline $\begin{array}{l}\text { Author and } \\
\text { reference }\end{array}$ & $\begin{array}{l}\text { Patient demo- } \\
\text { graphics }\end{array}$ & Brief summary \\
\hline Haden [6] & $\begin{array}{l}\text { A } 12 \text {-year-old girl } \\
\text { with tongue paralysis } \\
\text { after dental surgery }\end{array}$ & $\begin{array}{l}\text { Postoperatively, the patient stated she was unable to move her tongue and hypoglossal nerve injury } \\
\text { was suspected. The tongue had fasciculations and small movement was noted. MRI was normal. A } \\
\text { diagnosis of CD was made. She was evaluated by a family therapist and pediatric counselor. She } \\
\text { remained in the hospital for } 5 \text { days and gradually improved. }\end{array}$ \\
\hline $\begin{array}{l}\text { Reilly et } \\
\text { al [7] }\end{array}$ & $\begin{array}{l}\text { An 11-year-old } \\
\text { with torticollis and } \\
\text { neck pain after } \\
\text { tonsillectomy }\end{array}$ & $\begin{array}{l}\text { On postoperative day } 25 \text {, the patient presented to the ED with torticollis and trismus following an } \\
\text { uncomplicated tonsillectomy. No identifiable etiology for torticollis was identified as laboratory } \\
\text { studies and radiographic images were normal. After discussion with the family, it was determined } \\
\text { that the torticollis was intermittent, often associated with anxiety with medical intervention, and } \\
\text { absent during sleep. After a 4-day hospitalization, CD was diagnosed. At 6-week follow-up, the } \\
\text { patient's torticollis had resolved completely. }\end{array}$ \\
\hline $\begin{array}{l}\text { Judge and } \\
\text { Spielman [8] }\end{array}$ & $\begin{array}{l}\text { A 16-year-old } \\
\text { girl for Gelfoam } \\
\text { injection for left } \\
\text { vocal cord paralysis }\end{array}$ & $\begin{array}{l}\text { Following the procedure, the patient developed left-sided weakness involving her face as well } \\
\text { as all her extremities. Attempts at phonation were weak. A neurology consultation was obtained. } \\
\text { Electrolytes and imaging (CT, MRI) were normal. Psychological evaluation was performed } \\
\text { on postoperative day } 3 \text { and revealed anxiety and emotional distress with significant family life } \\
\text { stresses. On postoperative day } 8 \text {, she was discharged with follow-up appointments for physical and } \\
\text { psychiatric therapy. During recovery, she required the use of ambulatory assist devices for } 3 \text { months } \\
\text { but was then able to resume her normal social activities. }\end{array}$ \\
\hline Ryu et al [9] & $\begin{array}{l}\text { A } 13 \text {-year-old } \\
\text { girl with lower } \\
\text { extremity paralysis } \\
\text { after laparoscopic } \\
\text { appendectomy }\end{array}$ & $\begin{array}{l}\text { On postoperative day } 2 \text {, the patient presented with hypoesthesia and weakness in the right lower } \\
\text { extremity. She was unable to sense light touch between the T11 and L } 2 \text { dermatome. Her motor } \\
\text { strength of right hip and knee were reduced to } 2 / 5 \text {. Pelvic and lumbar MRI were normal. The } \\
\text { paralysis persisted for } 10 \text { days. On postoperative day } 13 \text {, nerve conduction study was normal. She } \\
\text { underwent rehabilitation training twice daily with a physical therapy. On postoperative day } 22 \text {, she } \\
\text { was able to independently walk. On postoperative day } 23 \text {, a CD was diagnosed. At } 1 \text { month } \\
\text { follow-up, the patient improved gradually and returned to normal life activities. }\end{array}$ \\
\hline $\begin{array}{l}\text { Nelson and } \\
\mathrm{Wu}[10]\end{array}$ & $\begin{array}{l}\text { A } 13 \text {-year-old girl for } \\
\text { upper endoscopy }\end{array}$ & $\begin{array}{l}\text { Patient had an acute onset of inspiratory stridor and unresponsiveness to verbal stimuli in the PACU. } \\
\text { Later during the postoperative course, she developed sensory loss and the acute onset of right-sided } \\
\text { hemiplegia. Extensive workup including ENT consultation and MRI failed to reveal any organic } \\
\text { cause for the problem. Postoperatively, the patient's stridor and mental status gradually returned to } \\
\text { baseline. }\end{array}$ \\
\hline
\end{tabular}

CD: conversion disorder; ED: emergency department; PACU: post-anesthesia care unit; EGD: esophagogastroduodenoscopy; EUS: endoscopic ultrasound; ENT: ear, nose, and throat.

plied. Anesthesia was induced with intravenous propofol (250 $\mathrm{mg})$ and fentanyl $(100 \mu \mathrm{g})$ followed by placement of a size 3 laryngeal mask airway. Under ultrasound guidance, a 2-inch, 21-gauge Stimpulex ${ }^{\circledR}$ (B. Braun, Melsungen, Germany) was used to perform the femoral nerve block. Twenty milliliters of ropivacaine with $4 \mathrm{mg}$ of dexamethasone was injected around the femoral nerve. The patient tolerated the surgical procedure well and was transported to the post-anesthesia care unit (PACU). She initially presented with rigors in the PACU, for which she received meperidine $(10 \mathrm{mg})$. As she emerged from anesthesia, she was screaming hysterically which was initially assumed to be emergence delirium. She was stating that the surgery was done on the wrong leg and that her family would sue the hospital. She was not acknowledging the affected leg with the surgical dressing, and was inconsolable. In an effort to orient her to familiar surroundings, she was transported to phase two recovery to be near family. Her agitation and screaming persisted and continued to worsen. There was no response to the administration of intravenous midazolam (2 $\mathrm{mg})$ and dexmedetomidine $(20 \mu \mathrm{g})$. Additionally, there was no response to a single bolus dose of propofol $(0.5 \mathrm{mg} / \mathrm{kg})$. She re-emerged in the same state with worsening agitation, continued to scream threatening statements, and repeatedly stated that the surgeon operated on the wrong extremity. She was also intermittently shouting about interpersonal issues with her home life. As she was attempting to remove her intravenous catheter, monitors, and trying to flee, physical restraint by multiple perioperative personnel was necessary. After further discussion with family, it was decided to provide sedation in attempt to provide a smoother emergence from anesthesia. She was returned to the operating room for a propofol infusion with a dexmedetomidine bolus at the completion of the sedation. To rule out metabolic causes for the agitation, an arterial blood gas (ABG), electrolytes, calcium, glucose and hemoglobin were drawn intraoperatively. All values were within normal limits. At the conclusion of the hour-long sedation, she was then taken directly to a private room in phase two recovery with family present and familiar music playing as she emerged. After $30 \mathrm{~min}$, the patient awoke smoothly, but was still somewhat confused about her post-procedure state. The patient remained stable and was monitored for approximately two additional hours. Following that, an extensive education 
was provided to her mother and the patient was discharged home. Upon arriving home, the patient had returned to her pre-surgical baseline state, acting normally while conversing with friends on the phone and watching television. However, approximately $4 \mathrm{~h}$ after arriving home, the patient abruptly decompensated over $5 \mathrm{~min}$ and transitioned from baseline to hyperventilation with rigors. She began having illogical speech and became disoriented. Emergency medical services (EMS) were called and upon their arrival, midazolam $(5 \mathrm{mg})$ was administered intramuscularly. She was transported to the emergency room where two additional doses of midazolam were administered intranasally. The patient continued to have agitation and illogical speech. On examination, the patient was noted to be diaphoretic, tachycardic, with reactive pupils. The case was discussed with a toxicologist and anesthesiologist due to concern for neuroleptic malignant syndrome, serotonin syndrome, or malignant hyperthermia. A complete metabolic panel (electrolytes, liver function, renal function), ammonia, urine drug screen, ABG and creatinine phosphokinase were within normal limits. Risperidone was administered for sedation. Pediatric neurology and psychology consultants were consulted and the symptoms were thought to be related to profound anxiety related to a $\mathrm{CD}$. The patient was transferred to the pediatric intensive care unit. A dexmedetomidine infusion was administered overnight for approximately $12 \mathrm{~h}$. Upon awakening from sedation, the patient had returned to her baseline mental state. Clinical psychology was involved to further discuss the working diagnosis of altered mental status secondary to $\mathrm{CD}$. The patient was referred to a behavioral health clinic for biofeedback and for short term intervention therapy sessions, mainly to focus on coping skills from recent and profound stressors. The stressors included being an extremely competitive athlete and having the feeling of letting her teammates down, since she was unable to compete in swim meets as she was recovering from injury and surgery. In addition, likely stressors within the home as well as the overwhelming stressors of being a teenager contributed to her CD. After 1 month postoperatively, the patient started swimming and returned back to her daily activities. The patient felt that she did not need to continue her physical and psychological therapy as she felt better.

\section{Discussion}

$\mathrm{CD}$ is defined as an unconscious and involuntary process by which psychosocial needs, conflicts or stresses are expressed as somatic symptoms [1]. The signs and symptoms of CD do not conform to a known anatomical or physiological pattern. CDs may be precipitated by any traumatic or stressful event including the anxiety associated with the physiological impact of anesthetic care and a surgical procedure. Anecdotal reports have documented CDs in both children (Table 1) and adults following relatively minor surgical procures [6-14].

The diagnosis of CD according to the DSM-5 includes: 1) One or more symptoms of altered voluntary motor or sensory function. 2) Clinical findings that show evidence of incompatibility between the symptoms and recognized neurological or medical conditions. 3) Symptom or deficit that is not explained by another medical or mental disorder. 4) Symptom or deficit that cause clinically significant distress or impairment in social, occupational, or other vital areas of functioning and deserves medical evaluation [15].

Especially during the postoperative period, organic etiologies must be ruled out. In our case, before making a definitive diagnosis of $\mathrm{CD}$, other physiological causes were investigated and ruled out by a thorough history, physical examination, and laboratory evaluation including a complete metabolic panel (electrolytes, liver function, renal function), ammonia, urine drug screen, ABG, and creatinine phosphokinase. The differential diagnosis included emergence delirium, metabolic derangements (hypoxia, hypercarbia, hypoglycemia, hyponatremia), hypermetabolic syndromes (neuroleptic malignant syndrome, serotonin syndrome, anticholinergic syndrome, malignant hypertension), reaction to medications and other psychiatric conditions (hypochondriasis, factitious disorder, somatization and malingering). Additionally, based on the clinical presentation and physical examination findings, neurologic imaging may be needed to rule out hypoxic-ischemic or other anatomical causes.

There are four varied types of CD based on clinical presentation including those with 1) sensory deficits, 2) motor deficits, 3) pseudo-seizures, and 4) a mixed presentation [16]. The common physical complaints or deficits related to CD noted in the perioperative period have included loss hemiplegia, visual loss, new-onset paralysis, aphonia, inspiratory stridor or seizures [9-14]. The most common CD is non-epileptic seizure (pseudo-seizure), which may be misdiagnosed as epilepsy, treated with anticonvulsant agents and thereby affecting the patient's quality of life $[17,18]$.

As outlined in Table 1, our review revealed only five previous reports of postoperative $\mathrm{CDs}$ in the pediatric population [6-10]. These included a 12-year-old girl with tongue paralysis lasting for 5 days after dental surgery, an 11-year-old boy with neck pain and torticollis for 2 weeks after tonsillectomy, a 16-year-old girl who presented with left-sided weakness involving her face as well as all her extremities after a gelfoam injection for left vocal cord paralysis, a 13-year-old girl with lower limb paralysis after laparoscopic appendectomy, and a 13-year-old girl with acute-onset inspiratory stridor and unresponsiveness to verbal or painful stimuli after an upper endoscopy. With our case and the five other pediatric patients previously described, there appears to be a strong relationship between the specific surgery or perioperative events, and the characteristics of the $\mathrm{CD}$. $\mathrm{CD}$ is more frequent in females than males with a higher incidence in adolescents [19]. Onset may be varied from the immediate postoperative period in the PACU to weeks later.

Management strategies should include strong therapeutic teamwork and incorporation of a goal-oriented treatment plan to ensure success. Psychotherapy is the preferred treatment aimed at elucidating the emotional bases of symptoms [20]. Physical therapy can be an effective method of treatment in cases with physical limitations [21]. Consultation with psychology and psychiatric services in recommended. Pharmacologic therapy may include antidepressant or anxiolytic agents based on previous psychiatric co-morbidity [22]. Our patient 
responded well to biofeedback and cognitive behavioral therapy (CBT); therefore pharmacological intervention was not needed. CBT is the mainstay treatment of children with somatoform disorders $[23,24]$. A better prognosis can be expected in patients who have had a shorter duration, sudden onset, an early identifiable stressor, lack of comorbid psychiatric disorders, and good premorbid functioning.

In summary, in our case, a lack of treatment or delay in diagnosis could have significantly altered the clinical course in our patient with the potential for increased morbidity. CD should be considered in the differential diagnosis of behavioral and physical disturbances during the postoperative when the clinical signs do not match the physical diagnosis of the expected clinical course. However, the diagnosis remains one of exclusion with the need for a focused physical examination, laboratory investigation, and radiologic imaging to rule out pathologic causes. Intervention at the earliest time may improve the outcome for treatment interventions and facilitate a return to normal activity for the patient [25]. The potential impact on the patient and family is illustrated by data showing that $82 \%$ of adults stop working for some period of time due to their symptoms and hospitalization in children have been reported for as long as 110 days [24, 26]. As with all therapeutic interventions, active involvement of the patient and family is mandatory at all steps along the treatment path.

\section{Grant Support}

None.

\section{Conflict of Interest}

None.

\section{References}

1. Kurlansik SL, Maffei MS. Somatic symptom disorder. Am Fam Physician. 2016;93(1):49-54.

2. Pehlivanturk B, Unal F. Conversion disorder in children and adolescents: clinical features and comorbidity with depressive and anxiety disorders. Turk J Pediatr. 2000;42(2):132-137.

3. Sar V, Islam S, Ozturk E. Childhood emotional abuse and dissociation in patients with conversion symptoms. Psychiatry Clin Neurosci. 2009;63(5):670-677.

4. Goodyer I. Hysterical conversion reactions in childhood. J Child Psychol Psychiatry. 1981;22(2):179-188.

5. Nicholson TR, Stone J, Kanaan RA. Conversion disorder: a problematic diagnosis. J Neurol Neurosurg Psychiatry. 2011;82(11):1267-1273.

6. Haden RA. Conversion reaction following anesthesia. Anesthesia. 2004;59(7):728-729.

7. Reilly MJ, Milmoe G, Pena M. Three extraordinary complications of adenotonsillectomy. Int J Pediatr Otorhinolaryngol. 2006;70(5):941-946.
8. Judge A, Spielman F. Postoperative conversion disorder in a pediatric patient. Paediatr Anaesth. 2010;20(11):10521054.

9. Ryu G, Song SH, Lee KH. Monolimb paralysis after laparoscopic appendectomy due to conversion disorder. Korean J Fam Med. 2014;35(6):321-324.

10. Nelson EJ, Wu JY. Postoperative conversion disorder presenting as inspiratory stridor and hemiparesis in a pediatric patient. Am J Case Rep. 2017;18:60-63.

11. Han D, Connelly NR, Weintraub A, Kanev P, Solis E. Conversion locked-in syndrome after implantation of a spinal cord stimulator. Anesth Analg. 2007;104(1):163165.

12. Nakagawa C, Shiraishi Y, Sato S. A case of conversion disorder showing transient hemiplegia after general anesthesia. J Anesth. 2010;24(3):496.

13. Hsieh MK, Chang CN, Hsiao MC, Chen WJ, Chen LH. Conversion paralysis after surgery for lumbar disc herniation. Spine (Phila Pa 1976). 2010;35(8):E308-310.

14. Afolabi K, Ali S, Gahtan V, Gorji R, Li F, Nussmeier NA. Postoperative conversion disorder. J Clin Anesth. 2016;30:21-23.

15. Widiger TA, Clark LA. Toward DSM-V and the classification of psychopathology. Psychol Bull. 2000;126(6):946963.

16. Feinstein A. Conversion disorder: advances in our understanding. CMAJ. 2011;183(8):915-920.

17. Baslet G, Seshadri A, Bermeo-Ovalle A, Willment K, Myers L. Psychogenic non-epileptic seizures: an updated primer. Psychosomatics. 2016;57(1):1-17.

18. Alsaadi TM, Marquez AV. Psychogenic nonepileptic seizures. Am Fam Physician. 2005;72(5):849-856.

19. Gold MA, Friedman SB. Conversion reactions in adolescents. Pediatr Ann. 1995;24(6):296-298, 301-292, 305296.

20. Ali S, Jabeen S, Arain A, Wassef T, Ibrahim A. How to use your clinical judgment to screen for and diagnose psychogenic nonepileptic seizures without video electroencephalogram. Innov Clin Neurosci. 2011;8(1):36-42.

21. Kaur J, Garnawat D, Ghimiray D, Sachdev M. Conversion disorder and physical therapy. Delhi Psych J. 2012;15(1):394-397.

22. Stonnington CM, Barry JJ, Fisher RS. Conversion disorder. Am J Psychiatry. 2006;163(9):1510-1517.

23. Ford CV. The somatizing disorders. Psychosomatics. 1986;27(5):327-331, 335-327.

24. Lempert T, Dieterich M, Huppert D, Brandt T. Psychogenic disorders in neurology: frequency and clinical spectrum. Acta Neurol Scand. 1990;82(5):335-340.

25. Croicu C, Chwastiak L, Katon W. Approach to the patient with multiple somatic symptoms. Med Clin North Am. 2014;98(5):1079-1095.

26. Krasnik CE, Meaney B, Grant C. A clinical approach to pediatric conversion disorder: VEER in the right direction. Canadian paediatric surveillance program. Available from: http:/www.cpsp.cps.ca/uploads/publications/ RA-conversion-disorder.pdf. [Last accessed on 2017 September]. 